\title{
Effect of terbium(III) chloride on the micellization properties of sodium decyl- and dodecyl-sulfate solutions
}

\author{
A.C.S. Neves, A.J.M. Valente *, H.D. Burrows, A.C.F. Ribeiro, V.M.M. Lobo \\ Department of Chemistry, University of Coimbra, 3004-535 Coimbra, Portugal
}

Received 21 August 2006; accepted 21 October 2006

Available online 27 October 2006

\begin{abstract}
The effect of $\mathrm{TbCl}_{3}$ on the aggregation processes of the anionic surfactants sodium decyl sulfate (SDeS) and sodium dodecyl sulfate (SDS) has been investigated. Electrical conductivity data, combined with $\mathrm{Tb}$ (III) luminescence measurements suggest that the formation of micelles involving $\mathrm{TbCl}_{3}$ and SDS occurs at concentrations below the critical micelle concentration $(\mathrm{cmc})$ of the pure surfactants; the formation of these mixed aggregates was also monitored by light scattering, which indicates that the addition of $\mathrm{TbCl}_{3}$ to surfactant concentration at values below the pure surfactant $\mathrm{cmc}$ results in a much greater light scattering than that found with pure sodium alkylsulfate surfactant micelles. This phenomenon is dependent upon the alkyl chain length of the surfactant. With $\mathrm{Tb}(\mathrm{III}) / \mathrm{DS}^{-}$, complexes are formed with a cation/anion binding ratio varying from 3 to 6 , which depends upon the initial concentration of $\mathrm{Tb}(\mathrm{III})$. This suggests that the majority of the cation hydration water molecules can be exchanged by the anionic surfactant. When the carbon chain length decreases, interactions between surfactant and Tb(III) also decrease, alterations in conductivity and fluorescence data are not so significant and, consequently, no binding ratio can be detected even if existing. The surfactant micellization is dependent on the presence of electrolyte in solution with apparent cmc being lower than the corresponding cme value of pure SDS.
\end{abstract}

(c) 2006 Elsevier Inc. All rights reserved.

Keywords: Terbium(III); Sodium dodecyl sulfate; Sodium decyl sulfate; Micellization parameters; Aggregation

\section{Introduction}

There is increasing interest in the interaction of trivalent and higher valent metal ions with surfactants in aqueous solutions for various reasons. The trivalent lanthanides are of particular interest because they form a homogeneous family with very similar chemical behaviour but with a wide range of spectroscopic and magnetic properties. They have been extensively used as luminescent probes in the investigation of metal-binding sites in biological materials $[1,2]$ as well as in the study of surfactant association in solution $[3,4]$. In addition, systems of SDS micelles with lanthanide ions have been used for studying magnetic field effects on geminate pair recombination of radicals [5], or photoinduced emulsion polymerization [6] and are also of increasing interest in relation to the mesomorphism of lanthanide salts of anionic amphiphiles

\footnotetext{
* Corresponding author. Fax: +351239827703.

E-mail address: avalente@ci.uc.pt (A.J.M. Valente).
}

for applications in materials $[7,8]$. Lanthanides incorporated in suitable mesoporous materials also show considerable potential for catalysis [9].

$\mathrm{The} \mathrm{Tb}(\mathrm{III})$ ion is of particular interest as a luminescent probe for detection of organic analytes in batch solutions and for fluorescence labelling in clinical chemistry and molecular biology [10-12]. Terbium(III) ions can form stable complexes or chelates with various organic ligands and undergo intramolecular energy transfer through the triplet state of the ligand to the emitting level of the lanthanide ion [13]. It has been also reported that the fluorescence intensity of $\mathrm{Tb}(\mathrm{III})$ is enhanced in the presence of cationic (e.g., cetyltrimethylammonium bromide) [14] or anionic (e.g., sodium dodecyl sulfate and sodium dodecylbenzene sulfonate) $[10,15]$ surfactants. It is therefore of interest to obtain more detailed information on the interaction of this cation with surfactants.

In a previous paper [16] we have shown that in the presence of $\mathrm{Eu}(\mathrm{III})$ the micellization parameters of SDS change, and it was suggested that this is due to the formation of mixed 
$\left(\mathrm{Eu}(\mathrm{III}) / \mathrm{DS}^{-}\right)$aggregates at concentrations below the SDS cmc, and that such aggregates are responsible for the enhancement of Eu(III) luminescence. The mechanism which permits such an increase in the lanthanide luminescence has been reported elsewhere [17] and is suggested to involve the replacement of water molecules by anionic surfactant groups, which decreases the nonradiative decay of the excited cation. We have also found that although interactions between trivalent lanthanide ions and surfactant micelles can occur, predominantly by electrostatic interactions [18], these do not affect the luminescent properties of the trivalent lanthanides.

In the present paper, based on electrical conductivity measurements, we describe the effect of $\mathrm{Tb}(\mathrm{III})$ on the structural properties of anionic surfactants with different chain lengths (sodium dodecyl sulfate and sodium decyl sulfate) over a wide concentration range around the cmc. This is complemented by results from luminescence and static light scattering. Particular attention is given to association processes which occur below the pure surfactant $\mathrm{cmc}$ for SDS and SDeS ([surfactant] < $\mathrm{cmc})$.

\section{Experimental procedure}

\subsection{Materials}

Terbium(III) chloride hexahydrate (99.9\%, Aldrich), sodium dodecyl sulfate, SDS (Merck-pro analysis) and sodium decyl sulfate, SDeS (Aldrich-pro analysis) were used as received. All solutions were prepared using Millipore-Q water. No control was made on the $\mathrm{pH}$, which was the natural value for each solution (see Section 3).

\subsection{Conductance measurements}

Solution electrical resistances were measured with a WayneKerr model 4265 automatic LCR meter at $1 \mathrm{kHz}$. A dip-type conductance cell with a cell constant of $0.0801 \mathrm{~cm}^{-1}$, uncertainty of $0.02 \%$, was used. Cell constants were measured using the procedure described elsewhere [19]. Measurements were taken at $25.00( \pm 0.01)^{\circ} \mathrm{C}$ in a Grant thermostat bath. Solutions were always used within $24 \mathrm{~h}$ of preparation. In a typical experiment, $100 \mathrm{~mL}$ of $\mathrm{TbCl}_{3}$ solution were placed in the conductivity cell; then aliquots of the sodium dodecyl-sulfate solution were added in a stepwise manner using a Methrom 765 dosimate micropipette. To keep the concentration of $\mathrm{Tb}(\mathrm{III})$ constant, the solvent used in the preparation of SDS and SDeS solutions was the same $\mathrm{TbCl}_{3}$ solution as that placed in the conductivity cell. The specific conductance of the solution was measured after each addition and corresponds to the average of three ionic conductances, determined using homemade software. The specific conductance of the solutions, $\kappa$, is calculated from the experimental specific conductance, $\kappa_{\exp }$, and corrected for the specific conductance of water, $\kappa_{0}: \kappa=\kappa_{\exp }-\kappa_{0}$. The critical micelle $(\mathrm{cmc})$ and aggregation (cac) concentrations were computed using the second derivative of the specific conductance as a function of surfactant concentration, as described elsewhere [20].

\subsection{Fluorescence technique}

For luminescence spectral measurements a Spex Fluorog 111 spectrofluorimeter was used in a right-angle configuration with excitation at $280 \mathrm{~nm}, 2.5 \mathrm{~nm}$ excitation bandwidth and $1.25 \mathrm{~nm}$ emission bandwidth

Static light scattering measurements were carried out using a Spex 111 spectrofluorimeter in $90^{\circ}$ configuration with the excitation monochromator set at $330 \mathrm{~nm}$, and the emission spectrum scanned between 360 and $390 \mathrm{~nm}$, following the indications of Mougán et al. [21] $1.25 \mathrm{~nm}$ excitation and emission slits were used.

\section{4. $p H$ measurements}

$\mathrm{pH}$ measurements were carried out with a Radiometer $\mathrm{pH}$ meter PHM 240 using an Ingold U457-K7pH conjugated electrode; $\mathrm{pH}$ was measured on fresh solutions, and the electrode was calibrated immediately before each experimental set of solutions using IUPAC-recommended $\mathrm{pH} 4$ and 7 buffers. From $\mathrm{pH}$ meter calibration a zero $\mathrm{pH}$ of $6.710( \pm 0.04)$ and sensitivity of $99.9 \%$ were obtained.

\section{Results and discussion}

\subsection{Electrical conductivity measurements}

Fig. 1 shows the effect of $\mathrm{TbCl}_{3}$ on the specific conductances of aqueous solutions of SDeS and SDS, at $25^{\circ} \mathrm{C}$. The cmc values for SDeS and SDS obtained from electrical conductivity measurements, $3.16( \pm 0.12) \times 10^{-2} \mathrm{M}$ and $8.24( \pm 0.15) \mathrm{mM}$, are in excellent agreement with those reported in literature (33 and $8.3 \mathrm{mM}[22]$ ).

In the presence of $\mathrm{Tb}(\mathrm{III})$, the electrical conductance of the solutions shows a further inflexion point; for $\mathrm{SDeS} / \mathrm{Tb}$ (III)- 0.8 mM-mix solution, it is possible to observe an inflexion point at $[\mathrm{SDeS}]=7.99 \mathrm{mM}$ (Fig. 1A, line b, $\left.\mathrm{cac}_{1}\right)$ that can be attributed to association between $\mathrm{Tb}(\mathrm{III})$ and decyl sulfate ions and consequent changes in the solution structure. At SDeS concentration around the $\mathrm{cmc}$ (Fig. 1A, line c), an apparent critical micelle concentration, $\mathrm{cmc}^{\mathrm{ap}}$, is also found. A similar trend is also observed for the SDS/Tb(III) system; however, in this case, for the same $\mathrm{Tb}(\mathrm{III})$ concentration, the alterations are considerably enhanced. Initially, the addition of SDS leads to an increase in the electrical conductance of the $\mathrm{SDS} / \mathrm{TbCl}_{3}$ mixture until a SDS $\mathrm{cac}_{1}$ is reached, line $\mathrm{b}^{\prime}$ in Fig. 1B, which is quite similar to those found to SDeS/Tb(III) mixtures. After this, further increases in SDS concentration lead to a decreased slope of $\kappa=f([\mathrm{SDS}])$ until a maximum interaction concentration (mic) is reached, line $\mathrm{c}^{\prime}$. Under these conditions, mixed aggregate formation will occur and, consequently, the increase of electrical conductivity is not so significant (the size of aggregate ionic species increases and the observed increase in the specific conductance are likely to be due to release of counter-ions); finally, at $[\mathrm{SDS}]>$ mic, the shape of the plot of electrical conductance as a function of [SDS] in the presence of $\mathrm{TbCl}_{3}$, is similar to that found in pure aqueous solutions. Under these conditions, 


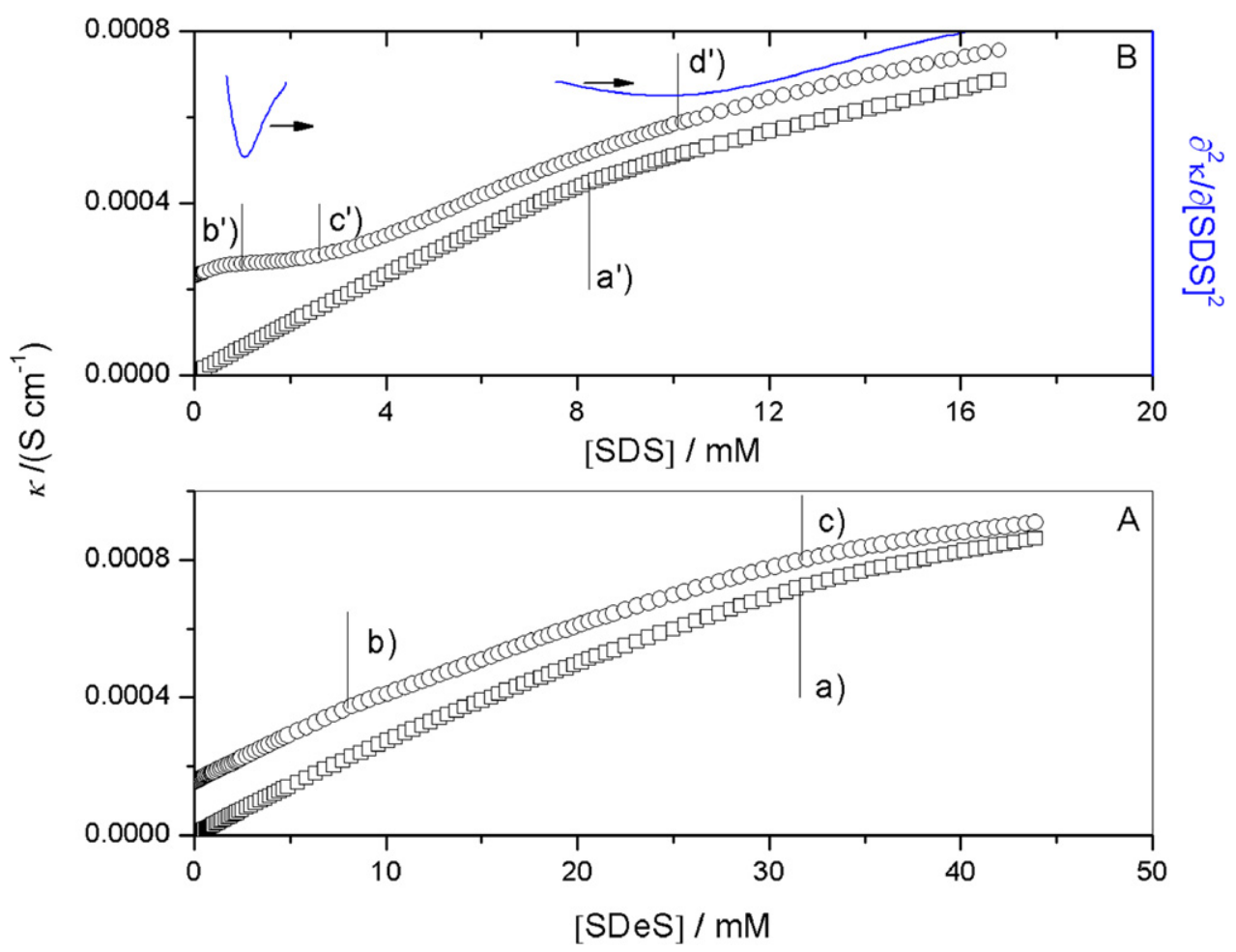

Fig. 1. Specific conductance of SDeS (A) and SDS (B) in water $(\square)$ and in aqueous solution of $\mathrm{TbCl}_{3} 0.8 \mathrm{mM}(O)$ at $25^{\circ} \mathrm{C}$. Vertical lines show inflexion points: (a) 31.6; (b) 7.99, and (c) $31.7 \mathrm{mM}$; ( $\left.\mathrm{a}^{\prime}\right)$ 8.24; ( $\left.\mathrm{b}^{\prime}\right)$ 0.998; ( $\left.\mathrm{c}^{\prime}\right)$ 2.61, and (d') $10.1 \mathrm{mM}$. In graph (B), the second derivative used in calculation of cac 1 and $\mathrm{cmc}^{\text {ap }}$ of SDS in SDS/Tb(III) system is shown.

no more $\mathrm{Tb}(\mathrm{III})$ is available to induce $\mathrm{DS}^{-} / \mathrm{Tb}(\mathrm{III})$ aggregate formation and/or the maximum aggregation number is reached, and after this, SDS will be in excess, such that the solution behaves in a similar way to pure SDS in aqueous solution, and a $\mathrm{cmc}^{\text {ap }}$ (line $\mathrm{d}^{\prime}$ ) in Fig. 1B is observed at [SDS] slightly higher than the cmc of pure SDS.

The surfactant concentration at which the cac $_{1}$ occurs corresponds to the region of onset of flocculation reported in systems involving SDS and the trivalent Al(III) ion [23,24], and we believe it to be due to formation of mixed sodium and terbium(III) dodecyl- and decyl-sulfate micelles. Similar behaviour is observed with Eu(III) [16].

Table 1 shows the effect of initial $\mathrm{TbCl}_{3}$ concentration on the $\mathrm{cac}_{1}$ and $\mathrm{cmc}^{\text {ap }}$ of SDeS and SDS. We may conclude that: (a) the influence of $\mathrm{Tb}$ (III) on the SDS micellization/aggregation behaviour is greater than that with SDeS; (b) the variation of $\mathrm{cac}_{1}$ as a function of initial $\mathrm{Tb}$ (III) concentration is dependent on the surfactant; (c) the effect of initial $\mathrm{Tb}$ (III) concentration on $\mathrm{cmc}^{\mathrm{ap}}$ is much more marked for SDS than for SDeS.

It is possible to observe that, in the case of SDeS-containing solutions, cac $_{1}$ decreases from 9.10 to $7.99 \mathrm{mM}$ (corresponding to a decrease of around $12 \%$ ) with the increase of the $\mathrm{Tb}(\mathrm{III})$ concentration (from 0.611 to $0.838 \mathrm{mM}$ ). This behaviour can be explained by the increase of terbium ions in solution, leading to a decrease in the critical aggregation concentration. However, in the case of SDS, with the exception of the two $\mathrm{Tb}$ (III) concentrations $(0.233$ and $0.656 \mathrm{mM})$ an increasing trend in the $\mathrm{cac}_{1}$ values is found, which shows that the hydrophobicity of the sur-
Table 1

Effect of $\mathrm{Tb}(\mathrm{III})$ concentration on the critical aggregation $\left(\mathrm{cmc}^{\mathrm{ap}}\right)$ and apparent critical micelle $\left(\mathrm{cac}_{1}\right)$ concentrations of SDeS and SDS, at $298.15 \mathrm{~K}$

\begin{tabular}{llr}
\hline $\begin{array}{l}{[\mathrm{Tb}(\mathrm{III})]} \\
(\mathrm{mM})\end{array}$ & $\begin{array}{l}\mathrm{cac}_{1}( \pm s) \\
(\mathrm{mM})\end{array}$ & $\begin{array}{l}\mathrm{cmc}^{\mathrm{ap}}( \pm s) \\
(\mathrm{mM})\end{array}$ \\
\hline & $\mathrm{SDeS}$ & $29.7( \pm 0.9)$ \\
0.402 & & $32.0( \pm 0.6)$ \\
0.611 & $9.10( \pm 0.35)$ & $32.5( \pm 0.9)$ \\
0.758 & $8.16( \pm 0.24)$ & $31.7( \pm 0.9)$ \\
0.838 & $7.99( \pm 0.21)$ & \\
& & \\
0.233 & $\mathrm{SDS}$ & $8.77(0.40)$ \\
0.303 & $0.64( \pm 0.07)$ & $9.05(0.24)$ \\
0.458 & $0.48( \pm 0.06)$ & $9.35(0.42)$ \\
0.530 & $0.59( \pm 0.05)$ & $9.63(0.47)$ \\
0.656 & $0.66( \pm 0.02)$ & $9.58(0.57)$ \\
0.702 & $0.55( \pm 0.03)$ & $9.73(0.24)$ \\
0.822 & $0.73( \pm 0.03)$ & $10.10(0.35)$ \\
\hline
\end{tabular}

factant alkyl chain has a major role on the $\mathrm{Tb}(\mathrm{III}) /$ surfactant aggregation. This shows up in the analysis of the $\mathrm{cmc}^{\text {ap }}$ for both surfactants-containing solutions. In fact, whilst the $\mathrm{cmc}^{\text {ap }}$ for SDeS seems to be independent of the $\mathrm{Tb}$ (III) concentration and quite similar to the corresponding $\mathrm{cmc}$, suggesting that the presence of $\mathrm{Tb}(\mathrm{III})$ does not affect micelle formation, there is an increase of $\mathrm{cmc}^{\text {ap }}$ with an increase of $\mathrm{Tb}(\mathrm{III})$ concentration with the SDS system, which reinforces the conclusion of the role of the hydrophobicity of the alkyl chain as a major factor for the $\mathrm{Tb}(\mathrm{III}) /$ surfactant aggregation. As with the $\mathrm{Eu}(\mathrm{III})$ system [16] this may be due to the growth of large (possibly cylindrical) aggregates. 


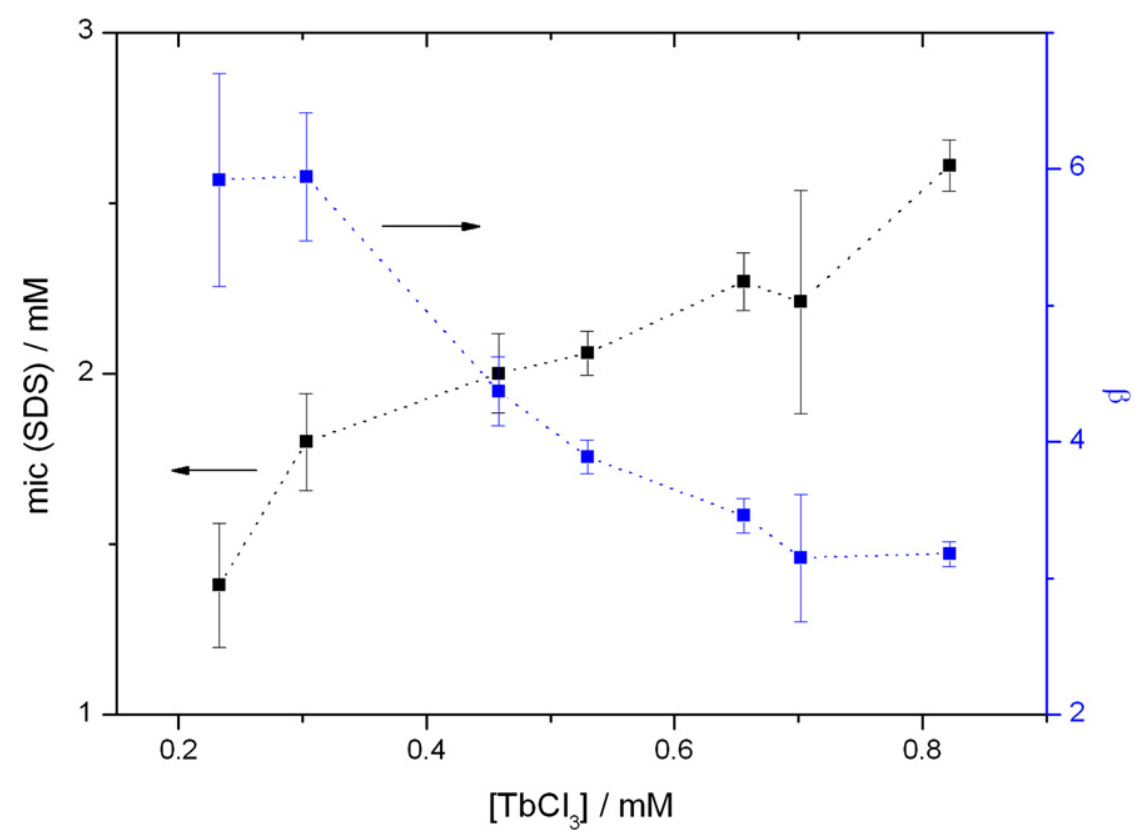

Fig. 2. Effect of initial terbium chloride concentration on the maximum interaction concentration (mic) and binding ratio $(\beta)$ between $\mathrm{SDS}_{\mathrm{S}} \mathrm{and} \mathrm{Tbl}_{3}$.

This is also supported by the effect of $\mathrm{Tb}(\mathrm{III})$ on the electrical conductance behaviour of SDS and SDeS as a function of concentration. Whereas, for SDeS, formation of aggregates occurs at $[\mathrm{Tb}(\mathrm{III})]>0.4 \mathrm{mM}$, the changes in the $\kappa=f([\mathrm{~Tb}(\mathrm{III})])$ are not so drastic as those occurring in the SDS system. With this system, it is possible to observe a further breakpoint, corresponding to the maximum interaction concentration (mic) of $\mathrm{Tb}(\mathrm{III})$ with the dodecyl sulfate ions. These results suggest that $\mathrm{TbCl}_{3}$ plays an important role in the formation of aggregates, and acts as a limiting reactant in such aggregates, supporting the idea that values of $\mathrm{cac}_{1}(0.64-0.78 \mathrm{mM})$ correspond to the $\mathrm{cmc}$ of terbium(III) dodecyl sulfate. Although we have been unable to find any literature values for comparison, this value seems reasonable, since it is intermediate between the lower limit of the value for lanthanum(III) dodecyl sulfate $(\mathrm{cmc} \geqslant 0.22 \mathrm{mM})$ [25] and those of the dodecyl sulfates of the divalent ions $\mathrm{Ca}^{2+}, \mathrm{Mg}^{2+}, \mathrm{Pb}^{2+}, \mathrm{Cd}^{2+}$ and $\mathrm{Zn}^{2+}$ (cmc values in the range 1.0-1.8 $\mathrm{mM}$ ) [26], and is close to the value reported by us for $\mathrm{Eu}(\mathrm{III})$ dodecyl sulfate [16]. Taking into account these assumptions, for the $\mathrm{SDS} / \mathrm{TbCl}_{3}$ system it is possible to establish a relationship between the mic and the binding ratio $\left(\beta=\mathrm{mic} /\left[\mathrm{TbCl}_{3}\right]\right)$, which gives us some indication about the association stoichiometry between $\mathrm{Tb}(\mathrm{III})$ and DS $^{-}$. Fig. 2 shows the effect of terbium(III) concentration in the micelle interaction concentration (mic) and in the binding ratio. We can see that with increasing $\left[\mathrm{TbCl}_{3}\right]$, the binding ratio, $\beta$, decreases from 6 to 3 , a situation similar to that observed with $\mathrm{DS}^{-} / \mathrm{Tb}(\mathrm{III})$ aggregates [16]. Hydrocarbon chain length also has an influence on the formation of aggregates since there is no evidence of total $\mathrm{Tb}(\mathrm{III})$ consumption in the presence of SDeS, suggesting that a mixture of species (ions, aggregates and counter-ions) may exist when SDeS micelle formation occurs. Considering the electrostatic interactions between $\mathrm{Tb}$ (III) and alkyl-sulfate chains, the interactions with water must also be taken into account. In support of this, SDeS shows a higher solubility in water than SDS, and the stronger interactions with this surfactant can also be seen through various thermodynamic properties $[27,28]$.

\subsection{Fluorescence spectra}

Luminescence measurements provide further evidences for aggregation at surfactant concentrations below the $\mathrm{cmc}$ of pure surfactant. Fig. 3 shows the effect of SDS on the luminescence spectra of aqueous terbium solutions. The emission of terbium drastically increases in the presence of small concentrations of SDS; when SDS concentration approaches and/or is higher than the cmc value, the $\mathrm{Tb}(\mathrm{III})$ luminescence emission intensity decreases again. Lanthanide ions present well-defined luminescence resulting from $\mathrm{f}-\mathrm{f}$ transitions. This may give information on both the coordination environment and the degree of hydration of these ions [29]. The $\mathrm{f}-\mathrm{f}$ transitions of ions such as $\mathrm{Tb}(\mathrm{III})$ are forbidden by both spin and Laporte selection rules, and hence have very low molar absorption coefficients [17]. This explains the very low luminescence at $558 \mathrm{~nm}$ in the absence of SDS. In the presence of surfactants the increase in intensity may be explained both by a decrease in the number of coordinated water molecules and by binding of $\mathrm{Tb}(\mathrm{III})$ to species of different charges, such as $\mathrm{DS}^{-}$, by forming new $\mathrm{DS}^{-} / \mathrm{Tb}(\mathrm{III})$ aggregates [18]. The results are fully consistent with the model of formation of $\mathrm{Tb}(\mathrm{III}) / \mathrm{Na}^{+}$dodecyl sulfate micelles below the cmc of pure SDS, and similar to those findings previously reported [16].

The effect of SDeS and SDS on the Tb(III) emission is dependent on the initial concentration of terbium chloride as it is shown in Fig. 4. Tb(III) emission intensity, $I$, at $558 \mathrm{~nm}$, in the presence of anionic surfactant is normalised with the emission intensity of $\mathrm{TbCl}_{3}$ in the absence of surfactant, $I_{0}$, at the same wavelength. 


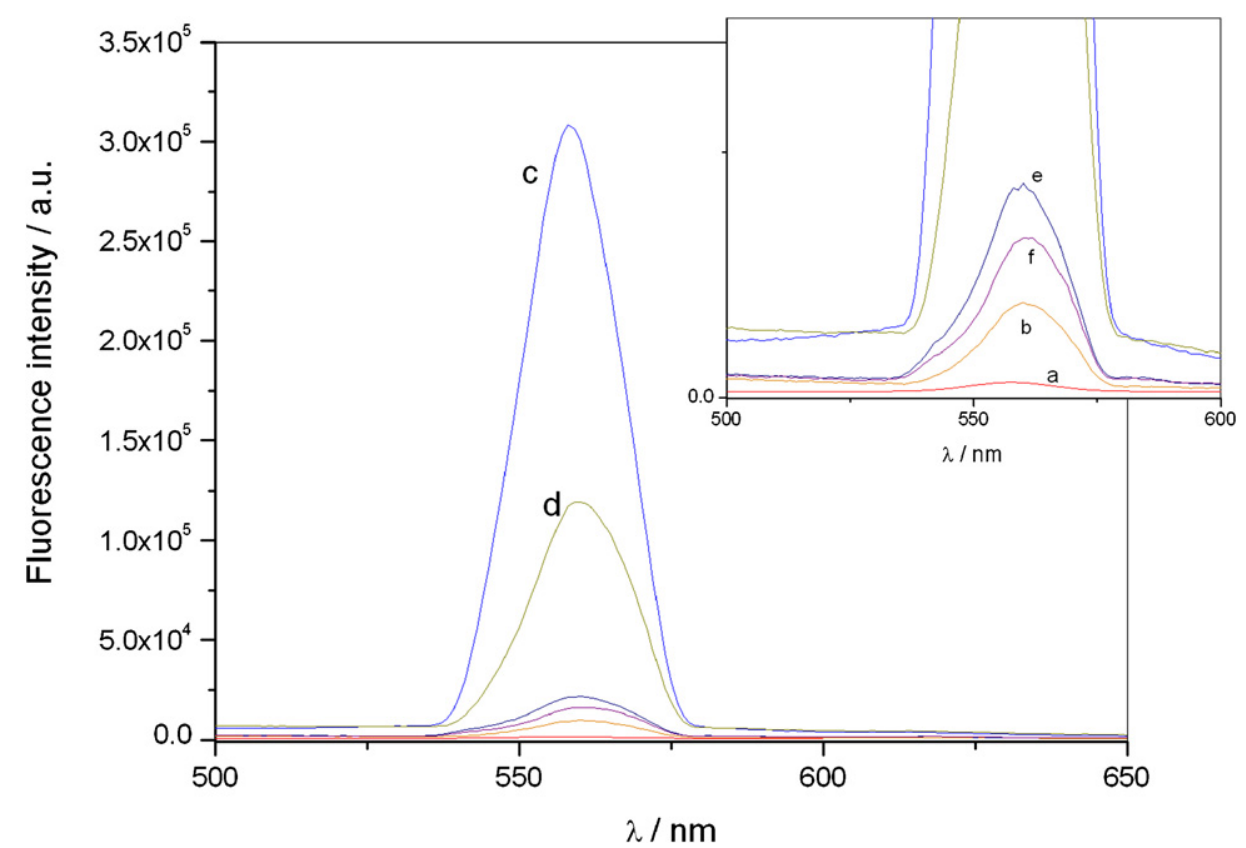

Fig. 3. Emission spectra of $\mathrm{Tb}(\mathrm{III}) 0.11 \mathrm{mM}$ with additions of different SDS concentrations at $25^{\circ} \mathrm{C}$ : (a) 0 (b) 1 (c) 3 (d) 5 (e) 7 , and (f) $10 \mathrm{mM}$. $\lambda$ exc $=280 \mathrm{~nm}$.
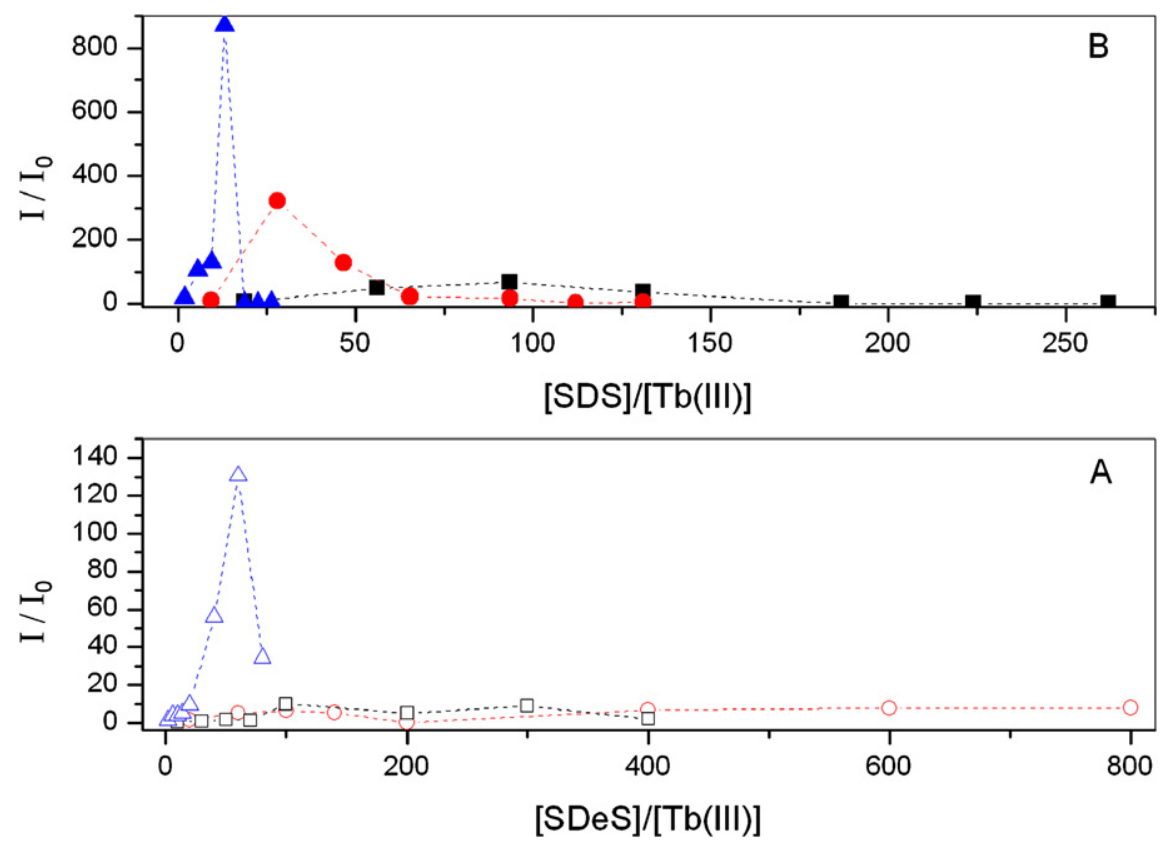

Fig. 4. Normalised maximum intensity fluorescence emission of $\mathrm{Tb}(\mathrm{III})$, in the presence of (A) SDeS and (B) SDS, in solutions with different initial concentrations

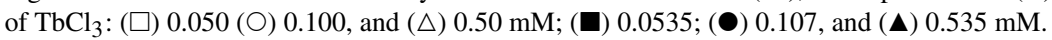

From Fig. 4 three major conclusions may be made: (a) it is possible to control the luminescence of $\mathrm{Tb}(\mathrm{III})$ by controlling the concentration ratio [anionic surfactant]/[Tb(III)], (b) the emission intensity is affected by the initial concentration of $\mathrm{TbCl}_{3}$, and (c) the effect of a $\mathrm{C}_{10}$ chain on the $\mathrm{Tb}(\mathrm{III})$ luminescence can be neglected at concentrations below $0.1 \mathrm{mM}$.

These results suggest that substituting coordinated water molecules by alkylsulfate anions is not the only condition for the increase in $\mathrm{Tb}(\mathrm{III})$ luminescence. For SDS-containing solutions (Fig. 4B), the maximum intensity ratio, $I / I_{0}$, for
$\left[\mathrm{TbCl}_{3}\right]=0.535 \mathrm{mM}$ is obtained for $[\mathrm{SDS}] /\left[\mathrm{TbCl}_{3}\right]=13$, whilst at $\left[\mathrm{TbCl}_{3}\right]=0.0535 \mathrm{mM}$ the maximum intensity ratio occurs at $[\mathrm{SDS}] /\left[\mathrm{TbCl}_{3}\right]=94$, etc.; i.e., the intensity follows an exponential decay of $[\mathrm{SDS}] /\left[\mathrm{TbCl}_{3}\right]$ as a function of the maximum $I / I_{0}$. The luminescence properties of $\mathrm{Tb}(\mathrm{III})$ in the presence of sodium decyl sulfate (Fig. 4A) show similarities to those found with SDS-containing systems. However, for the same $\mathrm{Tb}(\mathrm{III})$ concentration $(0.50 \mathrm{mM})$, the intensity of $\mathrm{Tb}(\mathrm{III})$ emission in the absence of surfactant (with a maximum $I / I_{0}=131$ ) is less than that found for the corresponding 


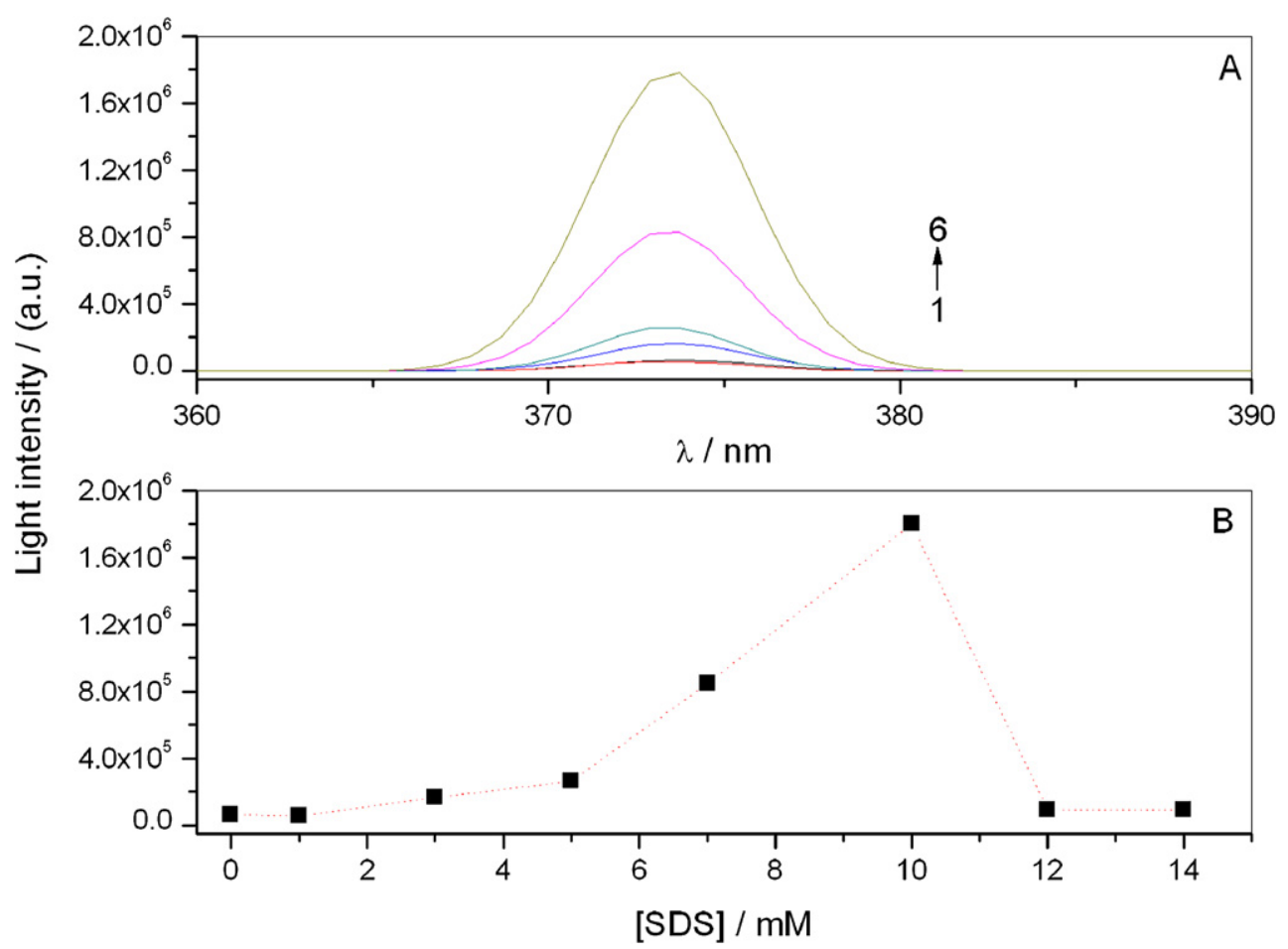

Fig. 5. Effect of SDS concentration on the light scattering of aqueous $\mathrm{Tb}^{3+}(0.5 \mathrm{mM})$ solutions. (A) Light scattering of $0.5 \mathrm{mM}^{3+} \mathrm{Tb}^{3+}$ solutions with SDS at concentrations below $\mathrm{cac}_{2}$ : (1) 0, (2) 1, (3) 3, (4) 5, (5) 7, and (6) $10 \mathrm{mM}$. (B) Light scattering intensity of SDS-Tb ${ }^{3+}$ solutions.

$\mathrm{SDS} / \mathrm{Tb}$ (III) solution (with a maximum $I / I_{0}=870$ ). It can also be noted that, in SDeS-Tb(III) solutions, only a slight increase of $I / I_{0}(<10)$ can be found for $[\mathrm{Tb}(\mathrm{III})]$ in the region 0.1 and $0.05 \mathrm{mM}$. If the main reason for the change in luminescence intensity is the decrease in the number of coordinated water molecules, this indicates that the exchange of coordinated water molecules by decyl sulfate ions at this $\mathrm{Tb}$ (III) concentration is not as efficient as that with dodecyl sulfate, which is in agreement with conductivity data, where break points other than the $\mathrm{cmc}$ are less marked with SDeS than with SDS.

Comparing data from conductivity with those obtained from luminescence, taking $[\mathrm{Tb}(\mathrm{III})]=0.5 \mathrm{mM}$ as reference, the maximum emission intensity is reached for [surfactant]/[Tb(III)] values around 60 and 13, which corresponds to concentrations $[\mathrm{SDeS}]=30 \mathrm{mM}$ and $[\mathrm{SDS}]=7.0 \mathrm{mM}$, respectively. These values are similar to those seen from conductivity measurements, and correspond to $\mathrm{cmc}^{\text {ap }}$ values (Table 1). That is, the maximum emission intensity is not reached when coordination water molecules are exchanged by alkylsulfate anions, i.e., corresponding to the $\beta$ values, Fig. 2, but when the alkylsulfate concentration approaches that corresponding to micelle formation with pure surfactant. Whilst conductivity measurements are affected by alteration of size of ionic species and consequently by alterations in the ionic mobility, luminescence is strongly dependent upon the local environment; however, from luminescence measurements, the $\mathrm{Tb}$ (III) emission passes through a maximum and decreases at high surfactant concentrations indicating that in the presence of micelles, $\mathrm{Tb}(\mathrm{III}) \mathrm{lu}-$ minescence quenching occurs.

\subsection{Static light scattering}

Further support for formation of SDeS- and SDS- $\mathrm{TbCl}_{3}$ aggregates at low (below the cmc of pure surfactant) surfactant concentrations comes from static light scattering. Taking SDS$\mathrm{Tb}$ (III) $0.5 \mathrm{mM}$ system as an example (Fig. 5), the addition of terbium(III) chloride to SDS solutions results in a continuously increasing scattering intensity between 0 and $10 \mathrm{mM}$ SDS, which corresponds to the beginning of SDS-micelle formation, according to conductivity data $\left(\mathrm{cac}^{\text {ap }}=9.63 \mathrm{mM}\right.$ to $[\mathrm{Tb}(\mathrm{III})]=0.53 \mathrm{mM})$. This seems reasonable, since it is known from both luminescence quenching studies [30], and EPR spin probe measurements [31], that micelle size is greater in the presence of higher valence ions than in pure SDS. This behaviour also occurs for SDeS- $\mathrm{TbCl}_{3}$ solutions. However, at concentrations above $10 \mathrm{mM}$ SDS, where both SDS micelles and terbium/sodium dodecyl sulfate aggregates are expected to be formed, light scattering decreases drastically. Possibly, with an increase in the number of SDS micelles, the population of $\mathrm{Tb}(\mathrm{III})$ ions in the mixed aggregates decreases, and thus leads to a decrease in their size.

The effect of the initial concentration of $\mathrm{TbCl}_{3}$ on the light scattering of SDeS- and SDS- $\mathrm{TbCl}_{3}$ mixtures was also analysed and is shown in Fig. 6.

We can see that the effect of [surfactant]/[Tb(III)] on the light scattering of surfactant- $\mathrm{Tb}^{3+}$ solutions follows a similar trend to that found with luminescence measurements, for both surfactants. Table 2 shows a comparison between surfactant concentrations at which maximum values for both luminescence and light scattering intensities are reached for 0.1 and $0.5 \mathrm{mM} \mathrm{Tb}$ (III) concentrations. The maximum light scattering 


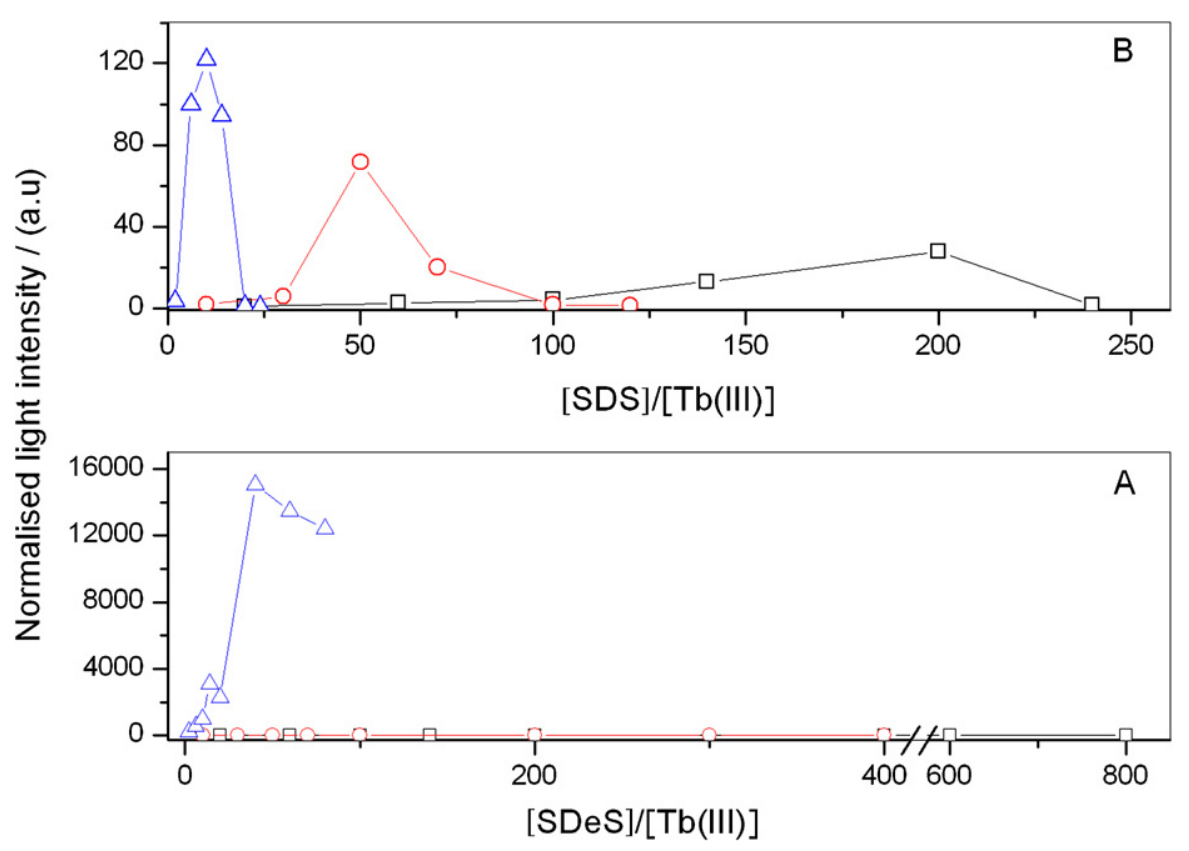

Fig. 6. Normalised light scattering intensity of $\mathrm{Tb}(\mathrm{III})$-sodium decyl-sulfate (A) and $\mathrm{Tb}(\mathrm{III})$-sodium dodecyl-sulfate (B) solutions, at different initial $\mathrm{TbCl} \mathrm{C}_{3}$ concentrations: $(\square) 0.050,(\bigcirc) 0.100$, and $(\triangle) 0.50 \mathrm{mM}$.

Table 2

Values of surfactant concentrations at which maximum values of fluorescence (F) and light scattering (LS) intensities are reached, for different initial $\mathrm{TbCl}_{3}$ concentrations

\begin{tabular}{lllll}
\hline $\begin{array}{l}{\left[\mathrm{TbCl}_{3}\right]} \\
(\mathrm{mM})\end{array}$ & $\begin{array}{l}{[\mathrm{SDeS}]_{\mathrm{LS}}} \\
(\mathrm{mM})\end{array}$ & $\begin{array}{l}{[\mathrm{SDeS}]_{\mathrm{F}}} \\
(\mathrm{mM})\end{array}$ & $\begin{array}{l}{[\mathrm{SDS}]_{\mathrm{LS}}} \\
(\mathrm{mM})\end{array}$ & $\begin{array}{l}{[\mathrm{SDS}]_{\mathrm{F}}} \\
(\mathrm{mM})\end{array}$ \\
\hline 0.1 & 30 & 10 & 5 & 3 \\
0.5 & 20 & 30 & 5 & 7 \\
\hline
\end{tabular}

intensity does not seem to depend on the surfactant concentration. With luminescence measurements, although the surfactant concentration necessary to reach the maximum emission intensity is of the same order of magnitude, there is an increase of the maximum surfactant concentration with an increase of initial $\mathrm{Tb}(\mathrm{III})$ concentration.

\section{4. $p H$ of aqueous $T b(I I I) /$ surfactant solutions}

Another point of interest is the fact that $\mathrm{cmc}^{\mathrm{ap}}>\mathrm{cmc}$ for both surfactants. One possible cause for an increase of the critical micelle concentration (i.e. $\mathrm{cmc}^{\text {ap }}$ ) of ionic surfactants is an increase of hydrogen ion concentration, since a decrease in $\mathrm{pH}$ is known to decrease surfactant association [32]. Therefore, the possible effect of $\mathrm{TbCl}_{3}$ hydrolysis [33] on the surfactants $\mathrm{cmc}^{\text {ap }}$ was studied. Fig. 7 shows the effect of surfactant on the $\mathrm{pH}$ of aqueous $\mathrm{TbCl}_{3}$ solutions. From this figure, two major conclusions may be obtained: (a) in the presence of surfactant the $\mathrm{pH}$ increases to values around neutrality and (b) the presence of micelles has a greater effect on the $\mathrm{pH}$ of the $\mathrm{TbCl}_{3}$ solution than that of surfactant unimers.

Fig. 7 shows that the hydrolysis of $\mathrm{TbCl}_{3}$ leads to a decrease in $\mathrm{pH}$ from around 6.7 (pure water) to around 5.0. However, in the presence of anionic surfactants a buffering effect occurs [34]. For $\mathrm{SDS} / \mathrm{Tb}$ (III) solutions the presence of micelles leads to a decrease of hydrogen ion concentration from $7.8 \mu \mathrm{M}$ to a final hydrogen ion concentration $0.363 \mu \mathrm{M}$ when compared with $\mathrm{Tb}(\mathrm{III})$ solutions; in the presence of unimers the variation in $\left[\mathrm{H}_{3} \mathrm{O}^{+}\right]$is slightly smaller, varying from 7.3 to $0.63 \mu \mathrm{M}$. An identical trend is found for $\mathrm{SDeS} / \mathrm{Tb}(\mathrm{III})$ systems. In the presence of SDeS, the solution $\mathrm{pH}$ becomes closer to neutrality which can be justified by a marked increase in the ionic strength in the solution [35]. At SDeS concentration near the $\mathrm{cmc}$, and the lowest $\mathrm{Tb}$ (III) concentrations, some hydroxyl ions are released, suggesting that the $\mathrm{Tb}(\mathrm{III})$ hydrolysis mechanism is drastically affected by the presence of high concentrations of SDeS unimers. However, it seems that for both SDS and SDeS systems, hydrolysis cannot be the main factor responsible for $\mathrm{cmc}^{\mathrm{ap}}>\mathrm{cmc}$. Instead, comparison of this behaviour with that reported for surfactant-aluminium-containing solutions, such an increase in the concentration for micelle formation can be explained by the change from spherical to cylindrical aggregates [23,24]. If we consider that for SDeS cac 1 is the concentration at which surfactant- $\mathrm{Tb}$ (III) aggregates are formed, and for SDS the mic is the surfactant concentration necessary for complete association with all terbium chloride present in solution, as seen by conductivity data, a critical aggregation concentration, $\mathrm{cac}_{2}$, can be calculated for both surfactants according to $\mathrm{cac}_{2}(\mathrm{SDeS})=\mathrm{cmc}^{\mathrm{ap}}-\mathrm{cac}_{1}$ and $\mathrm{cac}_{2}(\mathrm{SDS})=\mathrm{cmc}^{\mathrm{ap}}-\mathrm{mic}$, respectively. Consequently, the values of the $\mathrm{cac}_{2}$ are lower than the corresponding $\mathrm{cmc}$ of surfactants, showing that the onset of surfactant micellization responds to added electrolyte, in agreement with literature data [36].

\section{Conclusions}

As indicated in Section 1, the interactions of trivalent lanthanide ions with anionic surfactants are of considerable practical importance. It has been shown that interactions between 


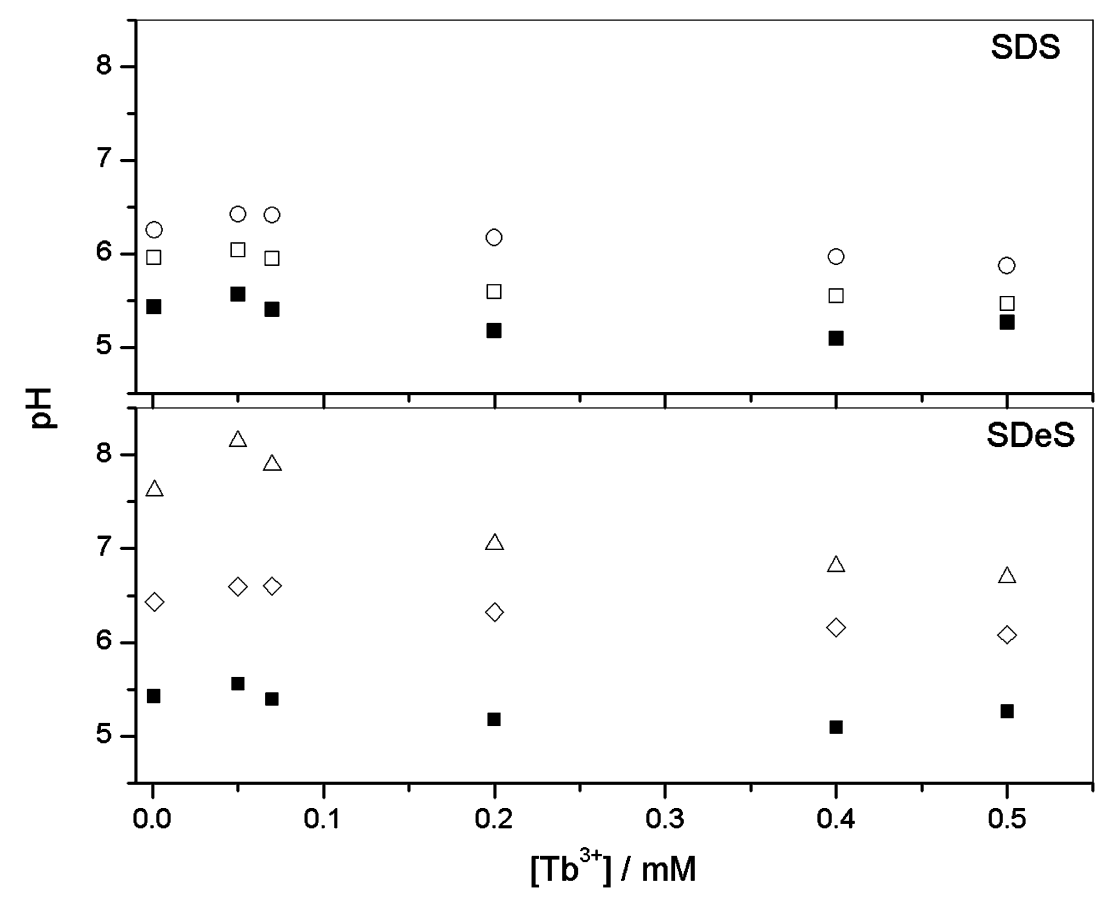

Fig. 7. Dependence of $\mathrm{pH}$ on addition of $\mathrm{TbCl}_{3}$ in aqueous solutions without (O) $14 \mathrm{mM}$.

$\mathrm{Tb}(\mathrm{III})$ ions and anionic surfactants (SDS and SDeS), in the unimer form, depend mainly on the balance between electrostatic forces and interactions between anionic hydrocarbon chain length and water; from electrical conductivity measurements, it is possible to observe association between $\mathrm{Tb}$ (III) and dodecyl sulfate at $\mathrm{Tb}$ (III) concentrations above $0.2 \mathrm{mM}$, which may be due to formation of terbium(III) dodecyl sulfate micelles. In contrast, no clear association between $\mathrm{SDeS}$ at $\mathrm{Tb}$ (III) concentration below $0.8 \mathrm{mM}$. These effects were confirmed by luminescence analysis where the effect of SDeS on the Tb(III) emission is only detected at $0.5 \mathrm{mM} \mathrm{Tb}$ (III) concentration. The difference in behaviour between the decyl and dodecyl sulfates suggests that aggregation in these systems involves a very careful balance between electrostatic interactions between cations and headgroups and hydrophobic interactions between alkyl chains.

In the presence of SDS the emission of $\mathrm{Tb}(\mathrm{III})$ can be observed to one order of magnitude lower $\mathrm{Tb}(\mathrm{III})$ concentrations. Such an effect can be explained by anionic surfactant association with the cation, whereby $\mathrm{Tb}$ (III) loses hydration water [18], and consequently emission is enhanced. This may have analytical applications, and addition of sodium dodecyl sulfate at low concentrations may be a useful route to enhancing lanthanide emission. However, at high surfactant concentrations $\mathrm{Tb}$ (III) ions or $\mathrm{Tb}(\mathrm{III}) /$ alkyl sulfate anions show a decreased emission intensity due to quenching by surfactant micelles. Over the $\mathrm{Tb}(\mathrm{III})$ concentration range studied, the $\mathrm{SDS}: \mathrm{TbCl}_{3}$ binding ratio change from 6 to around 3 when $\left[\mathrm{TbCl}_{3}\right]$ increases. Such a change can be justified by an alteration of the aggregate shape. At high concentrations, formation of cylindrical aggregates is suggested, in agreement with reports on the behaviour of aluminium dodecyl sulfates $[23,24]$. However, the $\mathrm{pH}$ dependence in the presence of terbium(III) appears to be somewhat different and less significant than that with aluminium(III), probably due to the smaller degree of hydrolysis of the lanthanide ion [33].

\section{Acknowledgments}

We are grateful for financial support from POCI/FCT/ FEDER.

\section{References}

[1] R.J.P. Williams, Struct. Bond. 50 (1982) 79.

[2] J.C.G. Bünzli, G.R. Choppin, Lanthanides Probes in Life, Chemical and Earth Sciences, Elsevier, Amsterdam, 1989, chaps. 6, 7.

[3] M.G. Miguel, H.D. Burrows, S.J. Formosinho, B. Lindman, J. Mol. Struct. 563-564 (2001) 89.

[4] M. Almgren, Adv. Colloid Interface Sci. 41 (1992) 9.

[5] N.J. Turro, X. Lei, I.R. Gould, M.B. Zimmt, Chem. Phys. Lett. 120 (1985) 397.

[6] N.J. Turro, K.S. Arora, Macromolecules 19 (1986) 42.

[7] E.F. Marques, H.D. Burrows, M.G. Miguel, J. Chem. Soc. Faraday Trans. 94 (1998) 1729.

[8] K. Binnemans, L. Jongen, C. Gorller-Walrand, W. D’Olieslager, D. Hinz, G. Meyer, Eur. J. Inorg. Chem. (2000) 1429.

[9] F.J. Berry, M. Carbucicchio, A. Chiari, C. Johnson, E.A. Moore, M. Mortimer, F.F.F. Vetel, J. Mater. Chem. 10 (2000) 2131.

[10] R.C. Rodriguez-Dias, M.P. Aguilar-Caballos, A. Gomez-Hens, Anal. Lett. 37 (2004) 1163.

[11] C.L. Tong, G.H. Xiang, W.P. Liu, Spect. Spectral Anal. 25 (2005) 2061.

[12] N. Arnaud, J. Georges, Anal. Chim. Acta 476 (2003) 149.

[13] N. Arnaud, J. Georges, Analyst 124 (1999) 1075.

[14] N. Arnaud, S. Drevet, J. Georges, Analyst 119 (1994) 2453.

[15] C.L. Tong, G.H. Xiang, D.J. Huang, H.P. Liu, Chin. J. Anal. Chem. 32 (2004) 619.

[16] A.J.M. Valente, H.D. Burrows, R.F. Pereira, A.C.F. Ribeiro, J.L.G.C. Pereira, V.M.M. Lobo, Langmuir 22 (2006) 5625. 
[17] M.J. Tapia, H.D. Burrows, Langmuir 18 (2002) 1872.

[18] M.J. Tapia, H.D. Burrows, M.E.D.G. Azenha, M.G. Miguel, A.A.C.C. Pais, J.M.G. Sarraguça, J. Phys. Chem. B 106 (2002) 6966.

[19] J. Barthel, F. Feuerlin, R. Neuder, R. Wachter, J. Solution Chem. 9 (1980) 209.

[20] P. Carpena, J. Aguiar, P. Bernaola-Galván, C. Carnero Ruiz, Langmuir 18 (2002) 6054.

[21] M.A. Mougán, A. Coello, A. Jover, F. Meijide, J.V. Tato, J. Chem. Educ. 72 (1995) 284.

[22] K. Holmberg, B. Jönsson, B. Kronberg, B. Lindman, Surfactants and Polymers in Aqueous Solution, second ed., Wiley, Chichester, 2003.

[23] F.I. Talens, P. Patón, S. Gaya, Langmuir 14 (1998) 5046.

[24] P. Paton-Morales, F.I. Talens-Alesson, Langmuir 17 (2001) 6059.

[25] J. Božić, I. Krznarić, N. Kallay, Colloid Polym. Sci. 257 (1979) 201.

[26] S. Miyamoto, Bull. Chem. Soc. Jpn. 33 (1960) 375.
[27] G.M. Musbally, G. Perron, J.E. Desnoyers, J. Colloid Interface Sci. 48 (1974) 494

[28] R. De Lisi, S. Milioto, N. Muratore, Langmuir 17 (2001) 8078.

[29] S.T. Frey, W.D. Horrocks, J. Inorg. Chim. Acta 229 (1995) 383.

[30] M. Almgren, S. Swarup, J. Phys. Chem. 87 (1983) 876.

[31] B.L. Bales, C. Stenland, J. Phys. Chem. 97 (1993) 3418.

[32] A.J.M. Valente, H.D. Burrows, A.Ya. Polishchuk, M.G. Miguel, V.M.M. Lobo, Eur. Polym. J. 40 (2004) 109-117.

[33] C.F. Baes Jr., R.E. Mesmer, The Hydrolysis of Cations, Wiley, New York, 1976.

[34] C.A. Bunton, K. Ohmenzetter, L. Sepulveda, J. Phys. Chem. 81 (1977) 2000

[35] V.M.M. Lobo, A.J.M. Valente, M. Araújo, Russ. J. Electrochem. 31 (1995) 451.

[36] P.C. Griffiths, J.A. Roe, B.L. Bales, A.R. Pitt, A.M. Howe, Langmuir 16 (2000) 8248. 